\title{
EVALUASI KUALITAS APLIKASI MOBILE KAMUS ISTILAH JARINGAN PADA PLATFORM ANDROID DENGAN STANDAR ISO/IEC 25010
}

\author{
Rohmad Dwi Jayanto \& Handaru Jati \\ Universitas Negeri Yogyakarta \\ e-mail: rohmaddwijayanto@gmail.com
}

\begin{abstract}
This research aims to understand the quality of the mobile networks dictionary application based on standard software quality testing ISO / IEC 25010 on functional suitability, compatibility, performance efficiency, and usability.The Research and Development $(R \& D)$ method was used. The result of this research indicate the application meets the standards of ISO / IEC 25010 on aspect of (1) functional suitability, entire functions of the application running 100\% no error found, (2) the compatibility of application, compatible 100\% of the co-existence, various operating systems, and device types, (3) performance efficiency, the application was succesfully executed in 436 of the 452 test devices on AWS Device Farm without any memory leak that can cause force close with the average of time behaviour, CPU utilization, memory utilization are 0.063 seconds/thread, 5\%, and $19 \mathrm{MB}$, (5) usability of application obtained a score of $83,22 \%$ that indicate this application proper on usability aspect
\end{abstract}

Keywords: dictionary, android, ISO/IEC 25010, quality apps, networks glossary

\begin{abstract}
ABSTRAK
Penelitian ini bertujuan untuk menguji aplikasi mobile kamus istilah jaringan komputer pada platform android menggunakan standar kualitas perangkat lunak ISO/IEC 25010 pada aspek functional suitability, compatibility, performance efficiency, danusability. Metode yang digunakan adalah research and development. Hasil dari penelitian ini menunjukkan bahwa aplikasi telah memenuhi standar ISO/IEC 25010 pada aspek (1) functional suitability seluruh fungsi dari aplikasi berjalan $100 \%$ yang artinya tidak ada fungsi yang gagal saat dilakukan pengujian, (2) compatibility aplikasi kompatibel 100\% darisisico-existence, berbagai sistem operasi dan tipe perangkat yang digunakan untuk pengujian, (3) performance efficiency aplikasi berhasil dijalankan di 436 dari 452 perangkatuji AWS Device Farm. Aplikasi berjalan dengan baik tanpa terjadi memory leak yang mengakibatkan aplikasi dipaksa berhenti (force close). Time behaviour utilization rata-rata aplikasi 0,063 seconds/thread, $C P U$ utilization aplikasi rata-rata 5\%, memory utilization aplikasi rata-rata $19 \mathrm{MB}$, dan (4) pengujian usability aplikasimemperoleh $83,22 \%$ yang artinya aplikasi sangat layak dari sisi usability.
\end{abstract}

Kata Kunci: kamus, android, ISO/IEC 25010, quality apps, networks glossary

\section{PENDAHULUAN}

Aplikasi mobile kamus istilah jaringan merupakan aplikasi kamus berbentuk aplikasi yang dapat dijalankan menggunakan perangkat smartphone Android. Aplikasi memiliki fitur search dan sharing dengan memuat 500 lebih kosakata didalamnya.Pengembangan sebuah aplikasi atau software sangat diperlukan untuk dilakukan pengujian tentang kualitas dari aplikasi tersebut, hal ini dimaksudkan agar ketika aplikasi sudah digunakan oleh pengguna, error atau kesalahan berupa ke tidak sesuaian fitur dapat dihindari (Rosa A. S. \& Shalahuddin, 2011).

Standar pengujian perangkat lunak sangatlah beragam, diantaranya The Bayesian Belief Network (BNN), Boehm, FURPS, McCall, Kazman, ISO 9126 dan ISO 25010. 
Dari beberapa standar pengujian diatas, ISO 25010 menjadi standar pengujian international dalam penentuan kualitas perangkat lunak yang sebelumnya dikenal dengan standar ISO 9126 (Mistrik, et. Al, 2016). Oleh karena itu pada penelitian ini, pengujian aplikasi mobile kamus istilah jaringan komputer menggunakan standar ISO 25010.

Berdasarkan latar belakang diatas, maka didapatkan rumusan masalah tentang bagaimana menjamin kualitas aplikasi mobile kamus istilah jaringan komputer agar tidak terjadi error ketika digunakan oleh pengguna? Tujuan dari penelitian ini yakni mengetahui tingkat kualitas aplikasi mobile kamus istilah jaringan komputer agar tidak terjadi error ketika digunakan oleh pengguna menggunakan standar pengujian perangkat lunak ISO 25010.

\section{METODE}

Penelitian "Pengembangan Aplikasi Mobile Kamus Istilah Jaringan Pada Platform Android" ini menggunakan metode pengembangan Research and Development (R\&D). Menurut Sudaryono (2014), Research and Development (R\&D) adalah metode penelitian yang digunakan untuk menghasilkan suatu produk dan menguji keefektifannya. Produk yang dihasilkan adalah aplikasi mobile kamus istilah jaringan. Olehkarena, itu untuk mendapatkan produk yang sesuai, maka dalam pengembangan perangkat lunak ini peneliti menggunakan proses pengembangan dengan tahapan model pengembangan perangkat lunak waterfall.

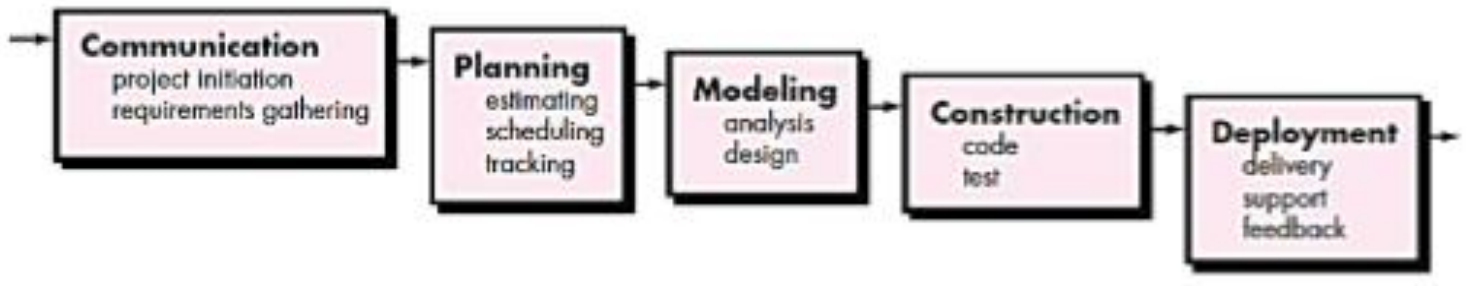

Gambar 1. Waterfall model (Pressman, 2010)

Waktu penelitian dilaksanakan pada bulan Juli 2016 sampai dengan Februari 2017. Tempat penelitian untuk pengembangan produk dilaksanakan di Laboratorium Program Studi Pendidikan Teknik Informatika Universitas Negeri Yogyakarta, sedangkan tempat untuk melakukan uji coba terhadap pengguna dilaksanakan di SMK N 2 Depok, Sleman, Yogyakarta. Subjek penelitian digunakan untuk menguji aspek usability, functional suitability dan uji materi dari produk yang telah dihasilkan. Pengujian functional suitability menggunakan 4 responden ahli dari berbagai profesi IT yang merupakan ahli dalam pengembangan perangkat lunak. Pengujian usability menggunakan 23 siswa kelas XI TKJ SMK N 2 Depok. Uji materi dilakukan oleh 2 ahli IT dalam bidang jaringan komputer, sedangkan pengujian performance efficiency dan compatibility menggunakan dokumentasi perangkatlunak.

Aplikasi mobile kamus istilah jaringan komputer diuji menggunakan standar pengujian kualitas perangkat lunak ISO/IEC 20510 dengan mengimplementasikan 4 aspek pengujian perangkat lunak mobile oleh Ben David (2010) yakni functional suitability, compatiblity, performance efficiency, dan usability. Aplikasi harus memenuhi seluruh aspek dari standar tersebut agar dapat dinyatakan layak. Selain itu, pengujian juga dilakukan terhadap konten aplikasi untuk mengukur kelengkapan materi.

Tahap pertama adalah uji materi. Pengujian materi bertujuan untuk memastikan bahwa konten atau materi yang ditampilkan aplikasi sudah lengkap dan uptodate. Instrumen pengujian ini menggunakan checklist dengan 3 pilihan apakah aplikasi 
layak digunakan, layak digunakan dengan perbaikan, dan tidak layak digunakan. Tahap kedua adalah pengujian functional suitability. Pengujian perangkat lunak aspek functional suitability menggunakan kuesioner yang berisi daftar fungsi yang dimiliki aplikasi dan menggunakan metode penilaian ahli (expert judgement). Kuesioner pengujian menggunakan model test case Orange HRM dari http://softwaretestinghelp.com. Tahap ketiga adalah pengujian compatibility. Aspek yang diuji meliputi Co-existence, Operating System, Device. Pengujian Co-existence dilakukan melalui observasi dengan cara menjalankan aplikasi kamus istilah jaringan bersama-sama dengan aplikasi lain. Pengujian ini akan menganalisis apakah aplikasi kamus istilah jaringan dapat berjalan berdampingan dengan aplikasi lain tanpa merugikan salah satu aplikasi. Pada aspek operating system, dan device menggunakan AWS Device Farm automatioan testing tool. Pengujian dengan AWS Device Farm secara otomatis akan menilai apakah aplikasi sudah kompatibel pada aspek-aspek uji tersebut. Tahap selanjutnya adalah pengujian performance efficiency. Aspek yang diujimeliputitime behaviour, CPU Utilization, dan Memory Utilization. Pengujian ini menggunakan AWS Device Farm yang secara otomatis akan menilai pengaruh aplikasi terhadap performa suatu perangkat. Tahap terakhir adalah pengujian usability. Pengujian usability menggunakan kuesioner yang dikembagkan oleh Lund A.M (2001) yakni USE Questionnaire. Kuesioner ini memiliki 30 pertanyaan yang terbagidalam 4 kriteria yakni usefullness, ease of use, ease of learning, satisfaction.

Teknik analisis data yang digunakan pada aspek Functional Suitability, Compatibility (Co-existence), danUsability adalah analisis deskriptif dengan rumus perhitungan (1).

$$
\begin{aligned}
& P K(\%)=\frac{\text { Skor yang diobservasi }}{\text { Skor yang diharapkan }} \times 100 \% \\
& \text { Keterangan: } \\
& P K(\%)=\text { PresentaseKelayakan }(\%)
\end{aligned}
$$

Setelah mendapatkan hasil presentase dari pengujian, presentase dikonversikan ke dalam pernyataan sesuai Tabel 1 (Sudaryono, 2011).

\begin{tabular}{lcl}
\multicolumn{2}{l}{ Tabel 1. Konversi } \\
\hline No & Presentase & \multicolumn{1}{c}{ Interpretasi } \\
\hline 1 & $0 \%-20 \%$ & $\begin{array}{l}\text { Sangat Tidak } \\
\text { Layak }\end{array}$ \\
2 & $21 \%-40 \%$ & Tidak Layak \\
3 & $41 \%-60 \%$ & Cukup Layak \\
4 & $61 \%-80 \%$ & Layak \\
5 & $81 \%-100 \%$ & Sangat Layak \\
\hline
\end{tabular}

Analisis pengujain compatibility pada aspek operating system, dan device menggunakan hasil yang didapatkan pada pengujian menggunakan AWS Device Farm dan Google Play Store. Sedangkan analisis performance efficiency pada aspek time behaviour, CPU Utilization, danMemory Utilization menggunakan rata-rata eksekusi thread per detik, penggunaan CPU, dan penggunaan memory dalam AWS Device Farm.

\section{HASIL}

Hasil dari penelitian ini diurutkan berdasarkan tahap pengujian. Perangkat uji yang digunakan adalah 6 perangkat yang tersedia di AWS Device Farm. Perangkatperangkat itu adalah LG Nexus, Samsung Galaxy S7, Samsung Galaxy S6 Edge, Sony Xperia Z3, OppoFind7a, L G2, Evercoss $A 26 B$. Perangkat-perangkat tersebut dipilih karena memenuhi kriteria keberagaman operating system, memory, dan device. Selain itu, aplikasi juga menggunakan 452 perangkat uji yang tersedia di AWS Device Farm untuk mendapatkan hasil pengujian secara umum.

Uji materi dilakukan dengan cara observasi untuk menilai konten aplikasi sudah uptodate atau belum. Hasil dari uji materi adalah aplikasi layak digunakan dengan penambahan beberapa penjelasan dari beberapa istilah. Uji Functional Suitability 
aplikasi dilakukan oleh 4 orang ahli dari berbagai profesi IT yang memahami sistematika pengembangan perangkat lunak. Hasil pengujian adalah $100 \%$. Hasil tersebut menunjukkan bahwa seluruh fungsi aplikasi dapat berjalan dengan baik sehingga memenuhi aspek functional suitability.

Uji co-existence dilakukan dengan cara observasi. Jenis aplikasi yang digunakan dalam pengujian ini meluputi Play Store, Google Chrome, Mobile Legends, Office Suite, Maps, Facebook Lite. Seluruh aplikasi tersebut dijalankan bersama-sama dengan aplikasi kamus istilah jaringan komputer dalam satu perangkat. Hasil dari pengujian ini adalah 100\% sehingga dapat disimpulkan bahwa aplikasi kamus jaringan komputer dapat berjalan dengan aplikasi lain dan memenuhi aspek compatibility co-existence. Pengujian compatibility dari sisi operating system dilakukan menggunakan AWS Device Farm. Sistem operasi yang digunakan adalah Android 4.1.2 sampai dengan Android 7.0. perangkat yang digunakan berjumlah 6 perangkat. Hasil dari pengujian ini $100 \%$ yang berarti aplikasi kamus istilah jaringan komputer memenuhi aspek compatibility dari sisi operating system. Pengujian compatibility dari sisi keberagaman device dilakukan menggunakan 6 perangkat yang sama dengan perangkat uji compatibility dari sisi operating system. Hasil pengujian adalah $100 \%$. Selain itu, pengujian juga dilakukan menggunakan 452 Device dari AWS Device Farm serta fitur compatibility pada Google Play Store Developer Console. Hasil dari pengujian AWS aplikasi dapat berjalan di 436 perangkat serta aplikasi kompatibel dengan 13271 jenis perangkat yang tersedia di Google Play Store. Hasil ini menunjukkan bahwa aplikasi kompatibel diseluruh perangkat pengujian. Oleh karena itu, dapat disimpulkan bahwa aplikasi kamus istilah jaringan memenuhi aspek compatibility dari sisi Device.

Pengujian performance efficiency menggunakan perangkat yang sama dengan pengujian sebelumnya dan dilakukan secara automation menggunakan tool dari AWS
Device Farm. Hasil ujiperformance efficiency aplikasi menunjukkan rata-rata penggunaan CPU adalah 5\%, rata-rata penggunaan Memory adalah 19MB, dantime behaviour rata-rata 0,063 seconds/ thread. Dari hasil tersebut, aplikasi kamus istilah jaringan komputer berjalan dengan baik tanpa mengalami memory leak yang dapat mengakibatkan force close apps.

Pengujian usability menggunakan USE Questionnaire yang berjumlah 30 butir dan diberikan kepada 23 responden. Hasil pengujian diperoleh persentase $83,22 \%$. Hasil tersebut menunjukkan aplikasi sangat layak dan memenuhi aspek usability.

\section{SIMPULAN}

Berdasarkan hasil penelitian dan pembahasan, maka dapat disimpulkan bahwa analisis kualitas aplikasi memperoleh hasil uji functional suitability sangat layak karena seluruh fungsi aplikasi berjalan $100 \%$. Sedangkan pada aspek compatibility sangat layak karena aplikasi dapat berjalan berdampingan dengan aplikasi lain, dapatberjalandiberbagai operating system, dan dapat berjalan pada berbagai versi android. Pada aspek performance efficiency dinyatakan layak karena aplikasi dapat berjalan baik di 436 dari 452 perangkat pengujian. Aplikasi dapat berjalan dengan baik tanpa terjadi memory leak dengan rincian penggunaan $\mathrm{CPU}$ rata-rata $5 \%$, penggunaan memory rata-rata $19 \mathrm{MB}$ dan memiliki rata-rata time behaviour 0,063 seconds/thread. Terakhir, uji usability aplikasi dinyatakan sangat layak dengan nilai $83,22 \%$. Oleh karena itu, secara umum aplikasi sangat layak digunakan.

Berdasarkan dari simpulan dan temuan dari penelitian yang telah dilakukan maka peneliti memberikan saran untuk pengembangan berikutnya perlu memaksimalkan fungsi dari aplikasi, penambahan kosakata secara berkala, serta penambahan beberapa fitur untuk memaksimalkan fungsi aplikasi. 


\section{DAFTAR PUSTAKA}

David, Assaf Ben. 2011. Mobile Aplication Testing Best Practices to Ensure Quality. Amdocs, 2.

ISO/IEC. 2011. Systems and software engineering - systems and software quality requirements and evaluation (SquaRE) - systems andsoftware quality models, 1. (I. J. 7,Editor). Diakses dari ISO:

http://iso.org/obp/ui/\#iso:std:isoec: 25010 pada 20 September 2016

Lund, A. M. 2001. Measuring Usability with USE Questionnaire. Usability and User Experience SIG. Diakses pada 20 September 2016. Dari http://www.stcsig.org/usability/newslett er/0110_measuring_with_use.html
Mistrik, I., Soley, R., Ali, N., Grundy, J., \& Tekinerrdogan, B. 2016.Software Quality Assurance: In large scale and complex software-intensive system. USA: Morga Kaufmann

Pressman, Roger. S. 2010. Software Engineering: A Practicioner's Approach (7th Edition). New York: McGraw-Hill.

Rosa, A.S. \& Shalahuddin. 2011. Model Pembelajaran Rekayasa Perangkat Lunak (Terstruktur dan berorientasi $i$ objek). Modula: Bandung

Sugiyono. 2014. Metode Penelitian Pendidikan Pendekatan Kuantitatif, Kualitatif, dan $R \& D$. Bandung: Alfabeta 